\title{
Insufficient social support for fathers of children with developmental disorders
}

Shiori Ishida (1) ${ }^{1 凶}$, Hiromi Okuno ${ }^{1}$, Hisato Igarashi ${ }^{1} \&$ Hiroko Takahashi ${ }^{1}$

Many parents carry exceptional burdens in childcare, especially while raising children with developmental disabilities (DD). Japanese local governments provide considerable support to mothers and their families, which indicates that such services are in high demand. However, similar assistance for fathers in the context of children with DD may be lacking. This study evaluated the social support status of fathers raising children with DD towards considering increased paternal support. Multiple-choice questionnaires on support for information ( 6 items), emotion ( 7 items), evaluation ( 3 items), and daily living ( 3 items) were completed by Japanese fathers $(n=85)$ and mothers $(n=101)$ of children with DD attending rehabilitation facilities. Regarding information support, fathers answered "spouse" as the main provider for all items, which differed significantly from mothers. For emotional support, fathers significantly more frequently received assistance from their workplace and spouse. Daily living support was also significantly more predominant for fathers in the workplace. Evaluation support sources were comparable between the respondent groups, with "spouse" being most frequently answered by fathers. These findings indicate a deficiency in external resources for fathers and support a need to consider increasing non-spouse resources and social support for fathers in raising children with DD.

\footnotetext{
${ }^{1}$ School of Health Sciences, Shinshu University, Nagano, Japan. ${ }^{凶}$ email: shioriis@shinshu-u.ac.jp
} 


\section{Introduction}

nfancy and early childhood are periods in which all aspects of child growth and development change remarkably (Institute for Juvenile Education, 2004). Parental involvement is a factor in childrearing (Masaki et al., 2011). However, many parents carry exceptional burdens in childcare, especially for raising children with developmental disabilities (DD) (Jellett et al., 2015; Nishijima et al., 2019; Nomura et al., 2020; Dissanayake et al., 2019). DD is defined in the Diagnostic and Statistical Manual of Mental Disorders, Fifth Edition, to include autism spectrum disorder (ASD), attention-deficit/hyperactivity disorder characterized by hyperactivity, impulsivity, and inattention, and learning disabilities with impairments in the ability to hear, speak, and reason, although overall intellectual development is not delayed (American Psychiatric Association, 2013).

In Japan, the Sukoyaka Oyako $21 \mathrm{~s}$ revision guidelines aim to promote childcare and family health support towards a society in which children grow up healthily (Ministry of Health, 2015). Fatherhood involvement is described as taking care of children, performing household chores, sharing the joy of raising children, and sharing the worries of child-raising while providing mental and physical care for the partner (Ministry of Health, 2021). Japanese local governments generally provide considerable medical, instructional, and emotional support to mothers and their families for child-raising, which indicates that such services are in demand. In particular, the parents of children with DD have a higher burden of childcare and more anxiety than do parents of healthy children, children with other disabilities, and children with chronic diseases (Kanematsu, 2015; Tsuda et al., 2012; Nakayama et al., 2013; Rachel et al., 2015; Dabrowska and Pisula, 2010; Lee, 2019). Thus, the importance of specialized and commensurate support appears even greater for DD.

Paternal participation in childcare is now being considered increasingly necessary to improve the child's mental development (Murakami et al., 2013). Active childcare involvement following social networking service-based training programs for fathers raising children with ASD resulted in a significant decrease in child-rearing stress, an increase in self-affirmation of childcare, and a better relationship with the child (May et al., 2021). Other studies have shown that paternal involvement in raising children with ASD reduces maternal stress and increases maternal family adaptability (Rankin et al., 2019). Even in the case of fathers raising children with stereotyped development, Maehara found that active nurturing was essential for the child's growth (Maehara et al., 2018). However, studies on assistance for fathers in the context of family support for children with DD requiring special care are lacking. A survey conducted in 2014 revealed that mothers had distinct differences from fathers in terms of childrearing situations, attitudes and thoughts, and anxieties on the upbringing of children in need of additional care. Moreover, the amount and kind of help required by Japanese fathers suggested a need to consider specific ways to support them that were different from those for mothers (Ishida et al., 2018).

The purpose of this study was to identify insufficiencies in social support for fathers towards considering increased assistance for the paternal care of children with DD.

\section{Methods}

Research subjects. The study participants were fathers and mothers of children attending rehabilitation centers for disabled preschool children (age range: $2-5$ years) from among 39 facilities in Nagano Prefecture, Japan. The investigation included 8 facilities following the approval of each facility director. A self-administered written questionnaire was mailed to participants after obtaining informed consent. Due to the young age of the children, only parental consent was obtained in this study. The survey period ranged from July to September 2016. This study was approved by our Institutional Ethics Committee (no. 4642) and was conducted in accordance with the Declaration of Helsinki.

Details of the investigation. The survey consisted of 19 items selected with reference to the Social Support Usage (contents and providers) items described by Ota (2010), the Code Matrix of Cases of Difficulties in Life for Mothers of Children with Developmental Disabilities reported by Yamashita (2013), and the Social Support Recognized by Mothers of Children with ASD items published by Fujita (2014). The 19 items were classified into four categories: information support (6 items), emotional support (7 items), evaluation support (3 items), and daily living support (3 items) (Table 1). Respondents were asked to indicate "yes" or "no" to sources of support among the four categories.

Statistical analysis. The survey results were subjected to chisquare testing between fathers and mothers. For items with an expected frequency of $<5$, Fisher's exact test was used to determine significance. A $p$-value of $<0.05$ was considered statistically significant. All analyses were performed using IBM SPSS Statistics version 22.0 for Windows (IBM, Chicago, IL, USA).

Ethical considerations. The purpose and voluntary nature of the study were specified in the questionnaire request form distributed to the subjects. Questionnaires were kept anonymous. No personal information other than basic attribute information was recorded. The respondents were assured that the survey results would be used for research purposes only.

\section{Results}

Response status. The surveys were sent to a total of 470 fathers and mothers. We received 186 completed questionnaires for a recovery rate of $39.6 \%$. Since there were no omissions for any of the response items, all 186 surveys were included in the analysis. The respondents included 85 fathers and 101 mothers.

Participant attributes. The attributes of the participants are shown in Table 2. The 85 fathers were a mean age of $40.7 \pm 8.8$ years. The 101 mothers were a mean age of $37.7 \pm 5.4$ years. Over $80 \%$ of the respondents in both groups reported being in good general health.

\section{Social support usage}

Information support. The paternal respondents indicated their spouse as the main provider of information support for all 6 items (Table 3). For items 1-6, fathers primarily responded "spouse" and "welfare organizations". These rates were all significantly different from the responses of mothers $(p<0.05)$. Regarding item 3, fathers answered "spouse" and "biological mother" as the top 2 sources of information support, which were also significantly different from the answers of mothers $(p<0.05)$. The maternal respondents cited "welfare organizations", such as kindergartens and developmental disorder support centers, as the main provider of information support for all 6 items (Table 3). Secondary sources of information included "welfare institutions" (items 1,2, 4, and 6; data not shown), "biological mother" (item 3), and "spouse" (item 5). Thus, the maternal caregivers tended to obtain child-raising information from a broader range of sources.

Emotional support. The paternal respondents answered "spouse" as the main provider of emotional support for all 7 items (Table 4). For items 1 and 2, fathers reported "spouse" and "welfare 
Table 1 Types of support and questions in the survey.

\begin{tabular}{|c|c|c|}
\hline Type & Questions & Category selections \\
\hline \multirow[t]{5}{*}{ 1. Information support } & 1. Information on developmental disorders (symptoms, course, treatment, etc.) & 1. "Spouse" \\
\hline & 2. Information and advice on medical care (how to deal with children) & 2. "Biological mother" \\
\hline & 3. General childcare information and advice & 3. "Mother-in-law" \\
\hline & $\begin{array}{l}\text { 5. Information and advice for balancing childcare of children with developmental } \\
\text { disabilities and work }\end{array}$ & 5. "Welfare organizations" \\
\hline & 6. Information on systems and services for children with developmental disabilities & \\
\hline \multirow{5}{*}{ 2. Emotional support } & 3. Consultation on personal problems and relationships & \\
\hline & 4. Consultation on all aspects of life, excluding child care, nursing, and work & \\
\hline & 5. Availability of someone who can listen to anything & \\
\hline & 6. Availability of someone close who gives a sense of security & \\
\hline & 7. Availability of someone who gives encouragement & \\
\hline \multirow{2}{*}{ 4. Evaluation support } & 2. Acceptance of one's methods on raising children with developmental disabilities & \\
\hline & $\begin{array}{l}\text { 3. Recognition of one's ideas and methods on raising children with developmental } \\
\text { disabilities }\end{array}$ & \\
\hline
\end{tabular}

\section{Table 2 Attributes of the respondents.}

\begin{tabular}{|c|c|c|}
\hline & Fathers & Mothers \\
\hline Age, years ${ }^{a}$ & $40.7 \pm 8.8$ & $37.7 \pm 5.4$ \\
\hline \multicolumn{3}{|l|}{ Educational background } \\
\hline High school graduate & $17(20.0)$ & $21(20.8)$ \\
\hline $\begin{array}{l}\text { Graduation from vocational school or junior } \\
\text { college }\end{array}$ & $23(27.1)$ & $44(45.6)$ \\
\hline Graduation from college or higher & $45(52.9)$ & $36(35.6)$ \\
\hline \multicolumn{3}{|l|}{ Employment situation ${ }^{\mathrm{b}}$} \\
\hline Full-time job & $78(91.8)$ & $12(11.9)$ \\
\hline Part-time job & $7(8.2)$ & $38(37.6)$ \\
\hline No job & $0(0.0)$ & $51(50.5)$ \\
\hline \multicolumn{3}{|l|}{ Family structure ${ }^{b}$} \\
\hline Parents and children & $68(80.0)$ & $78(77.2)$ \\
\hline Living with biological parents & $11(13.0)$ & $7(6.9)$ \\
\hline Living with parents-in-law & $5(5.8)$ & $14(13.9)$ \\
\hline Other & $1(1.2)$ & $2(2.0)$ \\
\hline \multicolumn{3}{|l|}{ Health condition ${ }^{b}$} \\
\hline Good & $76(89.4)$ & $83(82.2)$ \\
\hline Bad & $8(9.4)$ & $2(2.0)$ \\
\hline Unsure & $1(1.2)$ & $16(15.8)$ \\
\hline
\end{tabular}

organizations", which were significantly different from the responses of mothers $(p<0.05$ and $p<0.001$, respectively). For item 3, the top 2 paternal emotional support categories were "spouse" and "colleagues or bosses at work". These were significantly different from the answers of mothers $(p<0.001$ and $p<0.000$, respectively). For items $4-7$, fathers and mothers reported "spouse" as the main source at comparable rates. The maternal respondents cited "welfare organizations" as the main provider of support for items 1 and 2 (Table 4). For items 3-7, mothers answered "spouse" as the main provider. The second most common source tended to be "biological mothers" (items 3-6).

Daily living support. Fathers frequently listed "spouse" as the primary provider of daily living support (Table 5). For item 1,
The response percentage of "biological mother" was significantly lower than the answers of mothers $(p<0.01)$. Regarding item 2 , the response frequency of "spouse" was significantly higher than the responses of mothers. The response percentage of "colleagues or bosses at work", which included such support as an understanding of flexible working styles and recommendations for taking time off, was significantly higher than the answers of mothers $(p<0.000)$. For item 3, the response percentage of "colleagues or bosses at work" was significantly more frequent than the replies of mothers. Mothers cited "spouse" $(p<0.01)$ as the main provider of daily living support for all three categories, followed next by "biological mother" (items 1 and 2) or "biological mother" and "colleagues and bosses at work" equally (item 3) (Table 5). Thus, both parents primarily received help with daily living for childcare and housework from their spouse and biological mother. In terms of support at work, fathers tended to receive additional help from colleagues and superiors.

Evaluation support. Fathers answered "spouse", followed next by "biological mother", as the main provider of support for all 3 items (Table 6). For all items, the response frequency of "biological mother" was significantly lower than the replies of mothers $(p<0.01$ for items 1 and 2 and $p<0.000$ for item 3). Regarding the mothers' answers for evaluation support, the top 2 sources for all 3 items were "spouse" and "welfare organizations" (Table 6). Taken together, fathers were more likely to receive support from family members, while mothers tended to consult their family as well as non-family welfare organizations.

\section{Discussion}

The present study examined for insufficiencies in social support for fathers raising children with DD. In contrast to mothers, fathers tended to receive support from a narrower range of sources that was restricted primarily to close family members. These findings suggest a need to consider increased assistance for fathers from experts and external sources, such as advice on childcare from nursery school or rehabilitation center staff and other specialists, as well as asking grandparents for help in raising the child. 
Table 3 Information support survey results.

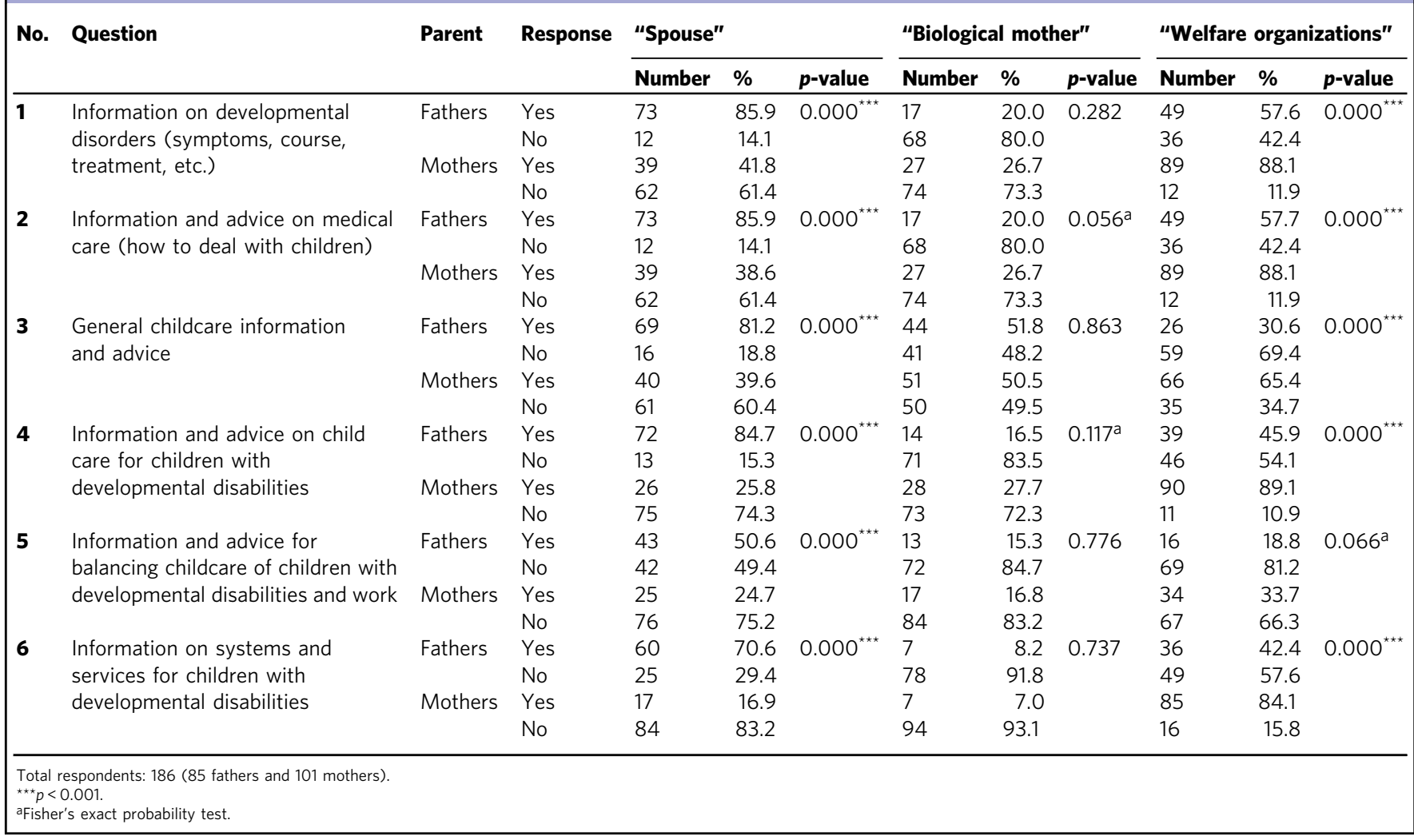

Support for obtaining necessary information for managing children with DD (category 1). In the case of fathers, the vast majority received information and advice on specialized knowledge and skills, such as understanding DD and child-raising methods, from their spouse, followed next by welfare organizations. The frequency of fathers who used specialized agencies as their primary information source was significantly lower than that of mothers. In their review of the literature on DD, Ishii et al. found that mothers who obtained reliable information exhibited a high degree of appropriateness in their child's disease management and behavior along with good mental health (Ishii and Asano, 2017). This may be missing among fathers based on the present study. Information provided from non-specialists can be imprecise and uncertain, which may lead to insufficient understanding and skill acquisition by the father about DD and complicate raising the child. Without a system providing reliable information, fathers may not be able to adequately respond to the needs of the child; this could raise the child's stress, reduce the father's interest in childrearing, increase the burden on the mother, and ultimately hinder the child's growth. Another possible reason for the minority of fathers receiving support from specialized institutions was the difficulty in finding the opportunity and time to visit centers due to work commitments. In considering the establishment of a paternity support system, it will be necessary to incorporate the circumstances and time limitations of fathers. Men in Japan typically work long hours, with frequent overtime and mandatory socializing with colleagues and customers (Ministry of Health, 2019; Nishida and Terashima, 2019). On the other hand, mothers primarily received support from specialists at welfare and medical organizations and presumably from contacts met through medical care and education, which indicated that they had access to a variety of useful and reliable sources. More than half of fathers received support from their spouses in obtaining information and counseling services to help them balance work and child-rearing responsibilities in the context of DD. However, few male respondents received support from their workplace or specialized institutions, indicating that they were unable to consistently get information from their company for raising their disabled child. Although the Japanese Work-Life Balance Charter 2008 states that society as a whole must support individuals and their families in order to achieve a proper work-life balance (Ministry of Health, 2007), the above findings suggest that such social systems have not yet been developed in terms of information support.

Emotional and evaluative support (categories 2 and 4). In the case of fathers, $\sim 70 \%$ of respondents cited their spouse as the main source of emotional support for all 6 items in category 2 . Such encouragement is critical in interpersonal relationships to decrease psychological stress via positive perceptions from others and the empathy described to be necessary for maintaining good relationships (Kato, 2002). The present survey indicated that fathers were most frequently empowered by their spouse's recognition of their parenting and their social life, including work. Apart from their spouse, fathers received limited emotional support from their biological mother (9.4-29.4\% for all items) and welfare organizations (1.2-21.2\% for all items). For item 3 in category 2 regarding consultations on personal problems and relationships, colleagues in the workplace were a notable source of support, cited by $47.1 \%$ of paternal respondents. In order to effectively raise children with $\mathrm{DD}$, it is deemed essential to enhance the so-called empowerment of the family through cooperation within families, between specialists and families, and between local governments and families (Wakimizu et al., 2011). For fathers to become more actively involved in the upbringing of children with DD, in addition to support from the spouse and specialized institutions, interactions with other families having 


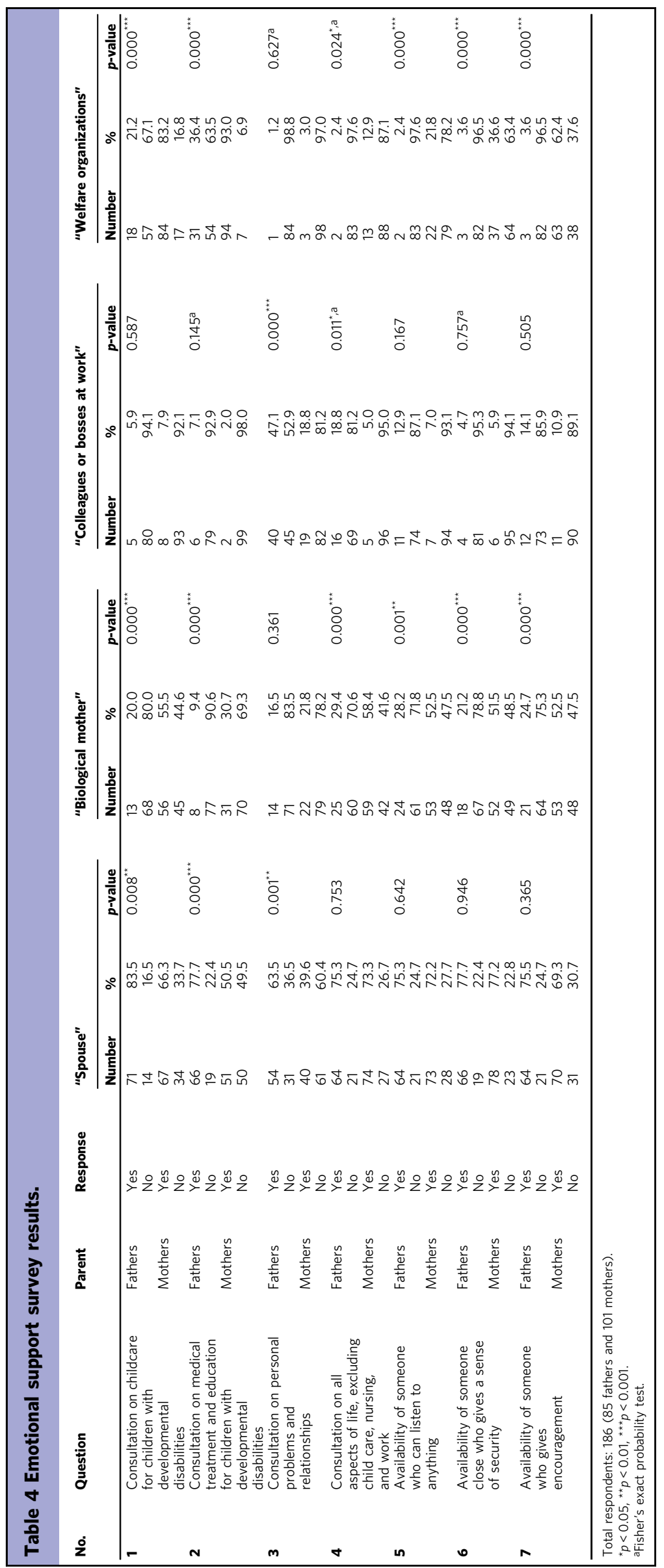




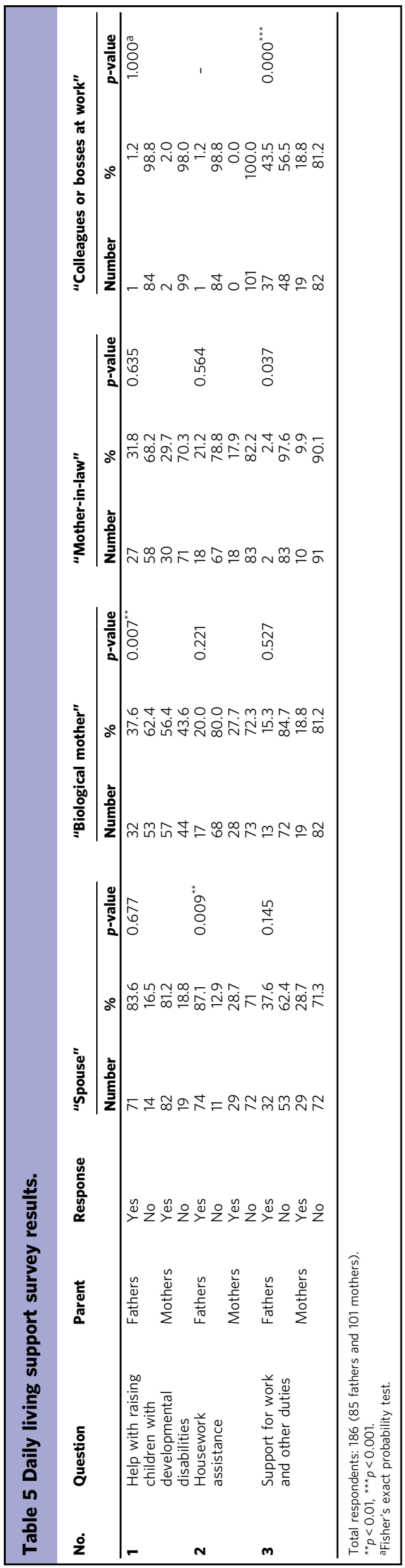

children with DD will also be a major factor (Ibuki et al., 2005). Fathers need more father-to-father connections and learning as well (Ishida et al., 2018), suggesting that an inter-family support system may be beneficial. In the case of mothers, a higher frequency of respondents answered that they had consulted with welfare organizations and specialists regarding the childcare and nursing of children with DD in addition to receiving emotional support from their spouse and biological mother. It was also evident that they obtained advice and peace of mind regarding their overall life from a wider range of sources than did fathers. Receiving emotional support from their spouse reduces anxiety about childrearing and enables mothers to think positively about childcare and maintain a smooth mother-child relationship (Mihara and Matsumoto, 2012). According to Yamashita et al. (2016), the father's high appreciation of the mother's parenting behavior and utmost support for the child help develop the mother's self-confidence and sense of efficacy as a parent. Also in the present study, fathers appeared to give psychological support to their spouses, which might have provided empowerment.

There were significant differences between fathers and mothers in the sources of evaluative support. The fathers of children with DD were limited to their spouse and biological mother for shaping their views and attitudes towards childrearing. On the other hand, mothers were seen to receive more support from outside the family, such as from welfare organizations, in addition to their spouse and biological mother. The reason for this may be that fathers primarily play a role in supporting the family's economic base by working and have fewer opportunities to establish relationships with support organizations than do mothers. Moreover, since fathers have more limited chances to obtain recognition from specialists and supporters other than family members, it is possible that they have difficulty in correctly understanding and responding to DD. Indeed, fathers appeared less able to receive the benefits of peer support to instill good feelings towards the child, confidence in childcare, and reduced childcare stress since they had fewer opportunities to be recognized by friends and others (Shimada et al., 2019).

Direct support for daily life (category 3). The main source of childcare and housework support was the spouse for both parents, with assistance from the biological mother or mother-in-law in the remainder of cases. Less than half of fathers received direct support for work and other duties from their colleagues or bosses, such as flexible work schedules (e.g., flextime) and recommendations for taking days off (Ministry of Health, 2020). These results indicated that couples tended to primarily support each other with childcare and housework duties. As the minority of respondents received support from other family members or work connections, the household burden on families containing children with DD may be considered as a result of increases in the number of nuclear families in Japan and the reported weakening of social capital (Ueda and Okamoto, 2011). Regarding extrahousehold support, it will be necessary to improve administrative services and establish better systems in local communities. A recent nationwide survey from Japan found that while the need for paternity initiatives was high in many municipalities, there was a clear discrepancy between awareness and actual practice (Ozaki, 2016). Therefore, it appears urgent to establish formal continuous support programs for fathers to connect with each other and learn specific measures for raising children, especially youths with DD.

Limitations and further research. The number of subjects included in this survey was small and might have been 
Table 6 Evaluation support survey results.

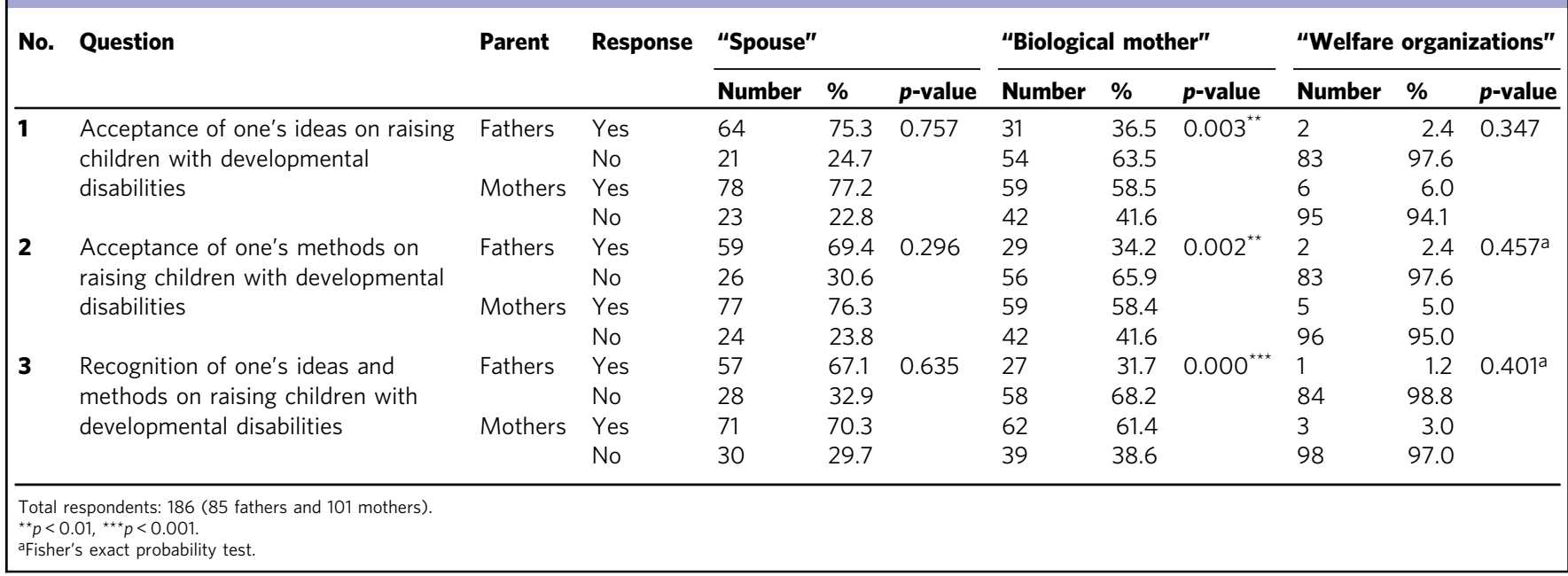

insufficient to consider all childcare situations; larger studies are needed to reduce possible selection bias and further identify other paternal challenges and information support needs. Future investigations should also aim to clarify the ideal family role for fathers of children with DD, the obstacles for not seeking support in some cases, and possible tailored assistance programs for fathers from experts and the government. Lastly, the findings in this report were obtained in Japan in reference mainly to preCOVID-19 studies and may not be directly applicable in other countries and circumstances. Especially with increases in remote working and limitations in public services due to the global COVID-19 pandemic, future studies will need to consider the rapidly changing face of working and childcare (Hirai and Watanabe, 2021).

\section{Conclusion}

In the upbringing of children with DD, Japanese fathers reported fewer social support sources as compared with mothers and were primarily dependent on their spouses. Consequently, a lack of adequate measures for understanding DD, such as the acquisition of appropriate coping methods and follow-up to maintain mental health, likely hinders the involvement of the father in raising children with DD. In addition to considering the development of a parenting support system for fathers and increased peer support, more detailed surveys are warranted on the actual condition of fathers' work-life balance and interfamily relationships to promote more concrete father support measures, empower fathers, and enhance paternal roles in raising children with DD.

\section{Data availability}

The datasets generated during and/or analyzed during the current study are not publicly available due to institutional confidentiality regulations but are available from the corresponding author on reasonable request.

Received: 20 August 2021; Accepted: 18 December 2021; Published online: 07 January 2022

\section{References}

American Psychiatric Association (2013) Behave: diagnostic and statistical manual of mental disorders, 5th edn, DSM-5. American Psychiatric Association, Washington
Dabrowska A, Pisula E (2010) Parenting stress and coping styles in mothers and fathers of pre-school children with autism and Down syndrome. J Intellect Disord Res 54(3):266-280. https://doi.org/10.1111/j.1365-2788.2010.01258.x

Dissanayake C, Richdale A, Kolivas N, Pamment L (2019) An exploratory study of autism traits and parenting J Autism Dev Disord 50:2593-2606

Fujita C (2014) Perceptions of social support by mothers of children with autism spectrum disorder (ASD) before and after enrollment in school. J Int Univ Health Welf 19:22-23

Hirai M, Watanabe H (2021) The impact of COVID-19 on the family and working life of fathers with young children. Jpn J Psychol. https://doi.org/10.4992/ jjpsy.92.20061

Ibuki M, Nakamura A, Nakano M, Murotani E et al. (2005) Child care anxiety of mothers of infants in the nuclear family Effect of environmental factors on child care anxiety. Bull Aino Gakuin 18:105-111

Institute for Juvenile Education (2004) Behave: Japanese version of the early childhood education handbook. Hikarinokuni Book, vol 33. Institute for Juvenile Education, pp. 1-212

Ishida S, Takahashi H, Igarashi $\mathrm{H}$ (2018) The role of fathers in supporting the growth of children with developmental disabilities using rehabilitation centers. Nagano Assoc Study Nurs 38:7-10

Ishii M, Asano M (2017) Relationship between the asthma control QOL and the independence for utilization of information among parents with toddlers who have asthma. J Pediatr Clin Allergy 15(3):377-381

Jellett R, Wood CE, Giallo R, Seymour M (2015) Family functioning and behavior problems in children with autism spectrum disorders the mediating role of parent mental health Clin Psychol 19(1):39-48

Kanematsu Y (2015) Behave: PSI childcare stress index revised edition. Employment Issues Study Group of General Incorporated Association. Employment Research Corporation

Kato T (2002) The development of the empathic coping scale and assessment of the relationship of empathic coping to psychological well-being. Jpn Soc Soc Psychol17(2):73-82. https://doi.org/10.14966/jssp.KJ00003724862

Lee GK (2019) Parents of children with high functioning autism: how well do they cope and adjust? J Dev Phys Disabil 21(2), 93-114 https://doi.org/10.1007/ s10882-008-9128-2

Maehara K, Shiba M, Watanabe H, Urata K (2018) Factors affecting child rearing by fathers of young children. Jpn J Matern Health 58(4):640-647

Masaki Y, Hashimoto S, Okutomi Y, Ikeda Y (2011) The relationship between selfimage and the child-rearing anxiety for mothers with preschool children. J Jpn Soc Child Health 70(60):725-730

May CD, St George JM, Lane S (2021) Fathers raising children on the autism spectrum: lower stress and higher self-efficacy following SMS (Text2dads) intervention. J Autism Dev Disord https://doi.org/10.1007/s10803-021-04925-w

Mihara H, Matsumoto K (2012) A study of the awareness of the lives of fathers of the handicapped-with reference to the age of the handicapped above or below the age of 18, the position of the handicapped child among the siblings, and whether wives are working or not. Jpn Soc Study Soc Welf 53(2), 108-118. https://doi.org/10.24469/jssw.53.2_108

Ministry of Health, Labor and Welfare (2007). Charter for work-life harmony. https://www.jil.go.jp/english/lsj/detailed/2012-2013/chapter2.pdf/view. Accessed 9 Jun 2020

Ministry of Health, Labor and Welfare (2019) 2nd Edition White Paper on measures to prevent death and injury from overwork. Chapter 1 situation of working hours and mental health measures "proportion of overworked hours 
of $49 \mathrm{~h}$ or more in foreign countries" https://www.mhlw.go.jp/wp/hakusyo/ karoushi/20/dl/20-1-1.pdf

Ministry of Health, Labor and Welfare (2015) Sukoyaka Oyako 21 (second revision guidelines). https://www.mhlw.go.jp/seisakunitsuite/bunya/kodomo/ kodomo_kosodate/boshi-hoken/sukoyaka-01.html. Accessed 29 Aug

Ministry of Health, Labor and Welfare (2020) Examples of activities of companies "Ikumen Corporate Awards". https://ikumen-project.mhlw.go.jp/ pdf/award_company2020.pdf

Ministry of Health, Labor and Welfare (2021) Labor and welfare. Work-life balance guide (2020 edition) https://ikumen-project.mhlw.go.jp/library/download/wlb/ file://C:/Users/Shiori\%20Ishida/Downloads/papa_dokuhon2020\%20(3).pdf

Murakami K, Aoki K, Shiokawa Y, Kutsunugi S, Tsujino K (2013) In what situations do fathers with young children develop impulsive emotions. Child Health 16(5):418-423

Nakayama K, Sasaki A, Tanuma R, Morita, K (2013) Efficacy of individualized parent training program for parents of pre-kindergarten children with developmental disorders. Jpn Acad Community Health Nurs 15:41-50. https://doi.org/10.20746/jachn.15.3_41

Nishida H, Terashima S (2019) Japanese work style and "Work-style reform" The problem of reducing long working hours and introducing telework Psychologist 9:61-70. http://hdl.handle.net/10112/16832

Nishijima M, Nishimoto E, Saito N (2019) Nature of difficulties felt by parents of preschool children with developmental disorders and factor related consultation requests to a parent mentor. J Jpn Acad Community Health Nurs 22(3):34-43. https://doi.org/10.20746/jachn.22.3_34

Nomura S, Okamitsu M, Nagata N et al. (2020) Characteristics of parents and their infants with autistic behaviors: parent infant interaction, parental depression, and parenting stress. J Med Dent Sci 67:31-39. https://doi.org/10.11480/ jmds.670004

Ota A (2010) Awareness of social support by mothers raising children with developmental disorders-focusing on support from families, colleagues and professional institutions. Study Child Educ 22:35-44

Ozaki Y (2016) Child research net. Nationwide survey on support for fathers in Japan. http://www.blog.crn.or.jp/report/02/233.html. Accessed 20 Feb 2019

Rankin JA, Paisley CA, Tomeny TS, Eldred SW (2019) Fathers of youth with autism spectrum disorder: a systematic review of the impact of fathers' involvement on youth, families, and intervention. Clin Child Fam Psychol Rev 22:458-477. https://doi.org/10.1007/s10567-019-00294-0

Shimada Y, Sugihara K, Hashimoto S (2019) Literature review on the actual state and effect of childcare support for mothers who experience childcare-related stress, anxiety, and difficulties. Bull Sci Nurs Res 7 (1):69-81

Tsuda Y, Tanaka M, Takahara M, Hashimoto T (2012) The effects of parent training for the parents having preschool children with high functioning pervasive developmental disorders. J Jp Soc Child Health 71:17-23

Ueda K, Okamoto $\mathrm{N}$ (2011) The needs of families who have handicapped children in a children's. J Child Health 70(2):270-279

Wakimizu R, Fujioka H, Hurutani Y (2011) Exploration of related factors of family empowerment for families rearing children with developmental disorders in Japan, with the family empowerment scale Japanese version. J Child Health 70(1):46-53

Yamashita A (2013) Study on the difficulties of mothers of children with developmental disabilities. Jpn Bull Soc Psychiatry 22:241-254
Yamashita T, Kato A, Ishida Y (2016) Preliminary study on the effects of childrearing stresses on mother's identity: focusing on father's childrearing behavior. Bull Jumonji Univ 47:25-40

\section{Acknowledgements}

The research reported in this publication was supported by The Japan Society for the Promotion of Science (Young Research) award number 19K19669. The authors would like to thank Trevor Ralph for his English editorial assistance.

\section{Competing interests}

No authors reported any financial or other conflicts of interest in relation to the work described. The authors declare no competing interests.

\section{Ethical approval}

This study was approved by the Ethics Committee of Shinshu University (no. 4642) and was conducted in accordance with the Declaration of Helsinki.

\section{Informed consent}

Informed consent from the parents in this investigation was obtained by an opt-in method via the distribution of an explanatory letter (including the study's significance, purpose, methods, and expected results) and a questionnaire, which was voluntarily completed by each participant. Due to their young age, informed consent was not obtained from the children in this study.

\section{Additional information}

Correspondence and requests for materials should be addressed to Shiori Ishida.

Reprints and permission information is available at http://www.nature.com/reprints

Publisher's note Springer Nature remains neutral with regard to jurisdictional claims in published maps and institutional affiliations.

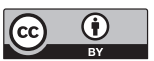

Open Access This article is licensed under a Creative Commons Attribution 4.0 International License, which permits use, sharing, adaptation, distribution and reproduction in any medium or format, as long as you give appropriate credit to the original author(s) and the source, provide a link to the Creative Commons license, and indicate if changes were made. The images or other third party material in this article are included in the article's Creative Commons license, unless indicated otherwise in a credit line to the material. If material is not included in the article's Creative Commons license and your intended use is not permitted by statutory regulation or exceeds the permitted use, you will need to obtain permission directly from the copyright holder. To view a copy of this license, visit http://creativecommons.org/ licenses/by/4.0/.

(C) The Author(s) 2022 